\title{
White spot syndrome virus (WSSV) infects specific hemocytes of the shrimp Penaeus merguiensis
}

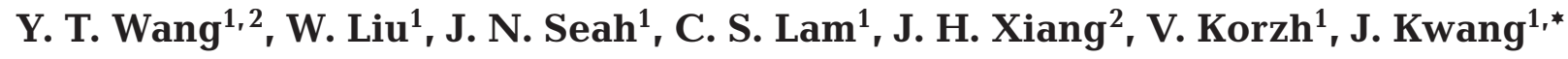 \\ ${ }^{1}$ Institute of Molecular Agrobiology, The National University of Singapore, Singapore 117604 \\ ${ }^{2}$ Institute of Oceanology, Chinese Academy of Science, 7 Nanhai Road, Qingdao, Shandong 266071, PR China
}

\begin{abstract}
White spot syndrome virus (WSSV) was specifically detected by PCR in Penaeus merguiensis hemocytes, hemolymph and plasma. This suggested a close association between the shrimp hemolymph and the virus. Three types of hemocyte from shrimp were isolated using flow cytometry. Dynamic changes of the hemocyte subpopulations in P. merguiensis at different times after infection were observed, indicating that the WSSV infection selectively affected specific subpopulations. Immunofluorescence assay (IFA) and a Wright-Giemsa double staining study of hemocyte types further confirmed the cellular localization of the virus in the infected hemocytes. Electron microscopy revealed virus particles in both vacuoles and the nucleus of the semigranular cells (SGC), as well as in the vacuoles of the granular cells (GC). However, no virus could be detected in the hyaline cells (HC). Our results suggest that the virus infects 2 types of shrimp hemocytes-GCs and SGCs. The SGC type contains higher virus loads and exhibits faster infection rates, and is apparently more susceptible to WSSV infection.
\end{abstract}

KEY WORDS: White spot syndrome virus $\cdot$ WSSV $\cdot$ Penaeus merguiensis $\cdot$ Hemocyte $\cdot$ Flow cytometry · Immunofluorescence assay $\cdot$ IFA

Resale or republication not permitted without written consent of the publisher

\section{INTRODUCTION}

White spot syndrome virus (WSSV) is a pathogen of major economic importance in cultured penaeid shrimp. The virus emerged during the early 1990s in Taiwan, from where it quickly spread to other shrimpfarming countries throughout the world (Inouye et al. 1994, Flegel et al. 1995, Huang et al. 1995, Wang et al. 1995, Lo et al. 1999). Almost all species of penaeid shrimp are susceptible to WSSV infection. In the cultured shrimp, WSSV infection can reach a cumulative mortality of up to $100 \%$ within 3 to $10 \mathrm{~d}$, and it causes enormous economic losses to the shrimp-culture industry worldwide (Lightner 1996). WSSV has become an epizootic disease and not only a major threat to shrimp culture but also to marine ecology in many of the shrimp-growing countries (Flegel 1997). Recently, the complete genome sequence of WSSV was reported (van Hulten et al. 2001, Yang et al. 2001).

${ }^{*}$ Corresponding author. Email: kwang@tll.org.sg
Crustaceans possess a primitive open vascular system (hemocoel). The blood is described as hemolymph and the blood cells are known as hemocytes (Lockwood 1968). Three different hemocyte types have been identified in shrimp hemolymph based on light- and electron-microscopy observations. The granular cells (GCs) contain large granules and have a low nucleusto-cytoplasm ratio, the semigranular cells (SGCs), with higher nucleus-to-cytoplasm ratio than GCs, contain mainly small granules, and the hyaline cells ( $\mathrm{HCs}$ ) are non-granulated but have a high nucleus-to-cytoplasm ratio (Martin \& Graves 1985, Sung et al. 1998). The present knowledge of the immune system of penaeid shrimp is limited. It is accepted that the hemolymph plays an essential role in disease prevention by means of cellular defenses that mainly rely on nonspecific immune responses such as coagulation, phagocytosis and encapsulation (Hose \& Martin 1989). Upon infection, large amounts of WSSV occur in gill tissues, stomach tissues, the midgut and in striated muscle (Chang et al. 1996, Lo et al. 1996a,b). However, very little is 
known about WSSV infective pathology in the hemocytes of shrimp. In this report, we attempt to link the relationship between the hemocytes and the WSSV, and reproduction of the virus herein. We analyzed which type of hemocytes could be associated with the WSSV, and we assessed the subcellular localization of the virions. Hemocytes were sorted by flow cytometry and each hemocyte type was further characterized for their infection status by immunofluorescence assay (IFA) and electron microscopy.

\section{MATERIALS AND METHODS}

Shrimp and hemolymph collection. Ten different batches of live shrimp, Penaeus merguiensis, 200 shrimp per batch, were delivered to our laboratory and consistently maintained in 5001 tanks equipped with air-lifted circulating seawater at room temperature. We used only juvenile shrimp, weighing on average 15 to $20 \mathrm{~g}$ (wet weight). Experimental shrimp, which came from a 'clean' (i.e. no visibly WSSV-infected shrimp) pond of a Malaysian farm and appeared to have no visible clinical symptoms, refused to take feed on the third day after arrival of each batch. On the fifth day, all experimental shrimp appeared lethargic and moribund. Approximately 1 to $2 \mathrm{ml}$ of hemolymph was collected from the cephalothorax of shrimp on 5 consecutive days (from the day of arrival, Day 1, to Day 5) using a 23-gauge hypodermic needle on a $2.5 \mathrm{ml}$ syringe filled with $0.5 \mathrm{ml}$ of $10 \%$ neutral buffered formalin (NBF) solution (10 $\mathrm{ml}$ of $37 \%$ formaldehyde solution in $90 \mathrm{ml} 0.01 \mathrm{M}$ PBS [phosphate-buffered saline], $\mathrm{pH}$ 6.9). The hemolymph samples were prepared according to Sung et al. (1999). In brief, samples were centrifuged at $300 \times g$ for $10 \mathrm{~min}$ at $4^{\circ} \mathrm{C}$ and then washed twice with modified complete Hank's balanced salt solution (MCHBSS) $\left(10 \mathrm{mM} \mathrm{CaCl}_{2}, 3 \mathrm{mM}\right.$ $\mathrm{MgCl}_{2}, 5 \mathrm{mM} \mathrm{MgSO}_{4}, 24 \mathrm{mg} \mathrm{ml}^{-1} \mathrm{HBSS}_{\text {; Gibco BRL). }}$ The hemocyte pellet was resuspended in MCHBSS containing $10 \%$ DMSO and stored at $4{ }^{\circ} \mathrm{C}$.

PCR detection of WSSV. For every batch of shrimp, $10 \%$ (20 shrimp) were randomly selected on Day 1 by PCR, which was carried out using a pair of oligonucleotide primers (Upstream Primer 144F: 5'-ATGGACGTGTCTGAGAGAATA-3'; Downstream Primer 144R: 5'-GTTACCAGGCAGGGGCCGTTCT-3') corresponding to the sequence of putative Open Reading Frame 144 (ORF 144) (Accession No. AF369029). Three different DNA templates were prepared from hemocytes, hemolymph (without anticoagulant) and plasma using a DNAzol kit (Gibco BRL). Purified WSSV DNA was included in the PCR-positive control, no DNA was added to the PCR-negative control. A $30 \mu$ reaction mixture was prepared in a thin-wall tube with $3 \mu l 10 \times$
Taq polymerase buffer (Qiagen), $0.3 \mu \mathrm{l}$ of each primer

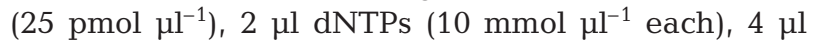
template DNA, $0.3 \mu \mathrm{l}\left(5{\left.\mathrm{U} \mathrm{l}^{-1}\right)}^{-1}\right.$ Taq polymerase and $20.4 \mu \mathrm{l}$ sterile distilled water. The tubes were placed in a GeneAmp9600 (PE Applied Biosystems) for amplification. After a pre-denaturing step at $94^{\circ} \mathrm{C}$ for $10 \mathrm{~min}$, a 50 cycle reaction was employed for the amplification. Each cycle consisted of $94^{\circ} \mathrm{C}$ for $1 \mathrm{~min}, 55^{\circ} \mathrm{C}$ for $1 \mathrm{~min}$ and $72^{\circ} \mathrm{C}$ for $1 \mathrm{~min}$. A final extension step of $72^{\circ} \mathrm{C}$ 10 min was applied. A $10 \mu \mathrm{l}$ aliquot of the product was subjected to electrophoresis on a $1.2 \%$ agar gel and photographed with an UV trans-illuminator. To confirm the positive results, bands of the expected size were gel-purified and sequenced using an ABI Prism BigDye terminator cycle sequencing ready reactions kit (Perkin Elmer).

Preparation of monoclonal antibodies. Monoclonal antibodies against $V p 28$ of WSSV were prepared as described in Liu et al. (2002). Briefly, spleen cells obtained from Balb/c mice that were immunized with 3 doses of purified recombinant $V p 28$ protein were fused with X63Ag8.653 mouse myeloma cells (ATCC) in the presence of PEG 1500. After screening and identification by ELISA and Western blot, hybridomassecreting monoclonal antibodies (Mabs) specific to WSSV were cloned. The supernatant fluids were collected from the hybridoma culture and used for IFA and immunogold election microscopy.

Immunogold electron microscopy. Hemolymph was fixed in $10 \%$ NBF and prepared as described above, and then collected by centrifugation. The pellet was washed twice with PBST $(0.1 \mathrm{M}$ PBS $+0.5 \%$ Triton $\mathrm{X}-100)$ and then blocked with blocking buffer $(10 \%$ $\mathrm{BSA}+\mathrm{PBST}$ ) for $1 \mathrm{~h}$ at room temperature. The Mab specific to Vp28 of WSSV (r-Vp28 Mab), diluted 1:500, was added and incubated overnight at $4^{\circ} \mathrm{C}$. After washing, gold-conjugated goat anti-mouse IgG (ICN), diluted 1:1000, was added and incubated for another 4 $\mathrm{h}$ at $4^{\circ} \mathrm{C}$. Between steps, samples were washed $(3 \times 15 \mathrm{~min})$ with PBST at room temperature. The samples were fixed again by immersion in $2.5 \%$ glutaraldehyde in $0.1 \mathrm{M} \mathrm{PBS}$ and post-fixed in $1 \%$ osmium tetroxide $(1 \mathrm{~h}$ each $)$ at $4{ }^{\circ} \mathrm{C}$. Finally, samples were dehydrated in an ethanol gradient, and embedded in Epok 812 resin (Oken). Ultrathin sections, $0.2 \mu \mathrm{m}$ thick, were prepared using the Porter-Blum MT-2B ultramicrotome (DuPont-Sorvall). Samples were stained with uranyl acetate, pH 6.0, and examined with an Hitachi $\mathrm{H}-700$ electron microscope at an accelerating voltage of $200 \mathrm{kV}$.

Sorting of shrimp hemocytes. Hemolymph randomly pooled from 10 shrimp of each batch, on Days 1 to 5 , was fixed in $10 \% \mathrm{NBF}$ solution. The hemocytes were prefiltered through a $200 \mu \mathrm{m}$ mesh gauze and suspended in shrimp salt solution (SSS, $450 \mathrm{mM} \mathrm{NaCl}$, 
$10 \mathrm{mM} \mathrm{KCl}, 10$ mM EDTA, 10 mM HEPES, pH 7.3, 850 mOsm kg-1; Rodriguez et al. 1995, Sequeira et al. 1996). Hemocytes were sorted based on their cellular granularity and cell sizes on a FACSCalibur sorter using the CellQuest program (Becton-Dickinson). Per sample, 20000 hemocytes were sorted and analyzed by immunofluoresence assay.

Immunofluorescence assay and hemocyte identification. Hemocytes sorted by FACSsort were harvested and suspended in SSS. A drop of the hemocyte suspension was spread on alcohol-cleaned glass slides, air-dried, fixed and permeabilized with acetone for 5 min. Antibody dilutions, washing and blocking steps were as described above. The slides were incubated with $\mathrm{r}-\mathrm{Vp} 28 \mathrm{Mab}$ overnight at $4^{\circ} \mathrm{C}$ followed by washing and further incubation in the dark at room temperature for 30 min with FITC (fluorescein isothiocynate)conjugated anti-mouse IgG (DAKO). Slides were fixed with acetone for $5 \mathrm{~min}$ and stained with WrightGiemsa in the dark for $30 \mathrm{~min}$ at room temperature. Finally, the slides were washed and rinsed with acetone and xylene (Le Moullac et al. 1997), respectively. Aqua Poly/Mount (Polysciences) mounted slides were observed under a phase-contrast microscope.

\section{RESULTS}

\section{PCR detection of WSSV}

A pair of primers, designed based on the 144th ORF from the WSSV genome sequence (AF369029), gave a satisfactory WSSV amplification, and these specific primers could also amplify WSSV ORF 144 in asymptomatic carriers. Based on the specific amplification of WSSV ORF 144, this primer pair was used throughout the study to determine the infection status of Penaeus merguiensis. A 282 bp product was amplified from the total DNA of hemocytes, hemolymph and plasma. WSSV was detected by PCR in all samples analysed (Fig. 1). The strongest signal from the hemocytes indicated the existence of the possible association of the WSSV with hemocytes. The bands were sliced from the gel and subsequently sequenced, showing 100\% homology with that of reported WSSV DNA.

\section{Immunogold electron microscopy}

The presence of virus in the hemolymph of infected shrimp was further examined by immunogold transmission electron microscopy. The intact viral particles found in hemolymph (Fig. 2a) exhibited a typical rodshaped morphology with an estimated (length $\times$ width) size of $280-350 \times 80-150 \mathrm{~nm}$, which fits the description

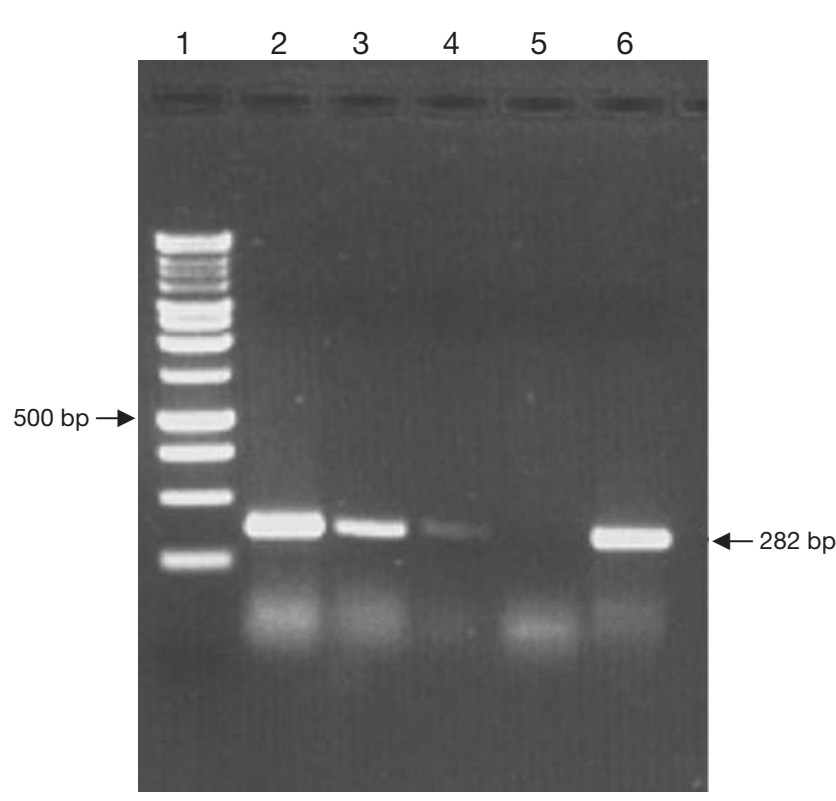

Fig. 1. Penaeus merguiensis. PCR amplification of 3 different samples collected on the day of arrival. Lane 1: $1 \mathrm{~kb}$ ladder; 2: total DNA of hemocytes; 3: hemolymph; 4: plasma; 5: negative control without DNA template; 6: positive control, purified WSSV DNA

of WSSV (Wang et al. 2000b). Mab specific to WSSV, labelled by numerous dense gold particles attached to the envelope of virions (Fig. 2b), further demonstrated that the virus found in the infected shrimp was WSSV. In the negative control, samples were treated with only secondary antibody (added gold-conjugated goat antimouse IgG) instead of Mab specific to WSSV, and no gold particle deposition was detected. These results suggest that the WSSV particles detected in the hemolymph were possibly released from the infected hemocytes and tissues after their collapse.

\section{Isolation of different types of shrimp hemocyte}

The separation of 3 hemocyte subpopulations is illustrated in Fig. 3a. These cells were defined as granular cells (GCs), semigranular cells (SGCs) and hyaline cells (HCs) (Lee et al. 2001). Flow cytometric studies revealed that the density of different types of hemocytes altered during the course of viral infection. Fig. 3a shows the estimated ratio of the 3 hemocyte subpopulations on Day 1 of the experiment. On Day 2, the GC and SGC subpopulations were significantly reduced (Fig. 3b) in the experimental shrimp. This trend continued up to Day 5, when the infected shrimp were moribund; furthermore, the SGC number was greatly diminished and the GC subpopulation level was reduced compared to Day 3 (Fig. 3c cf. Fig 3b), 


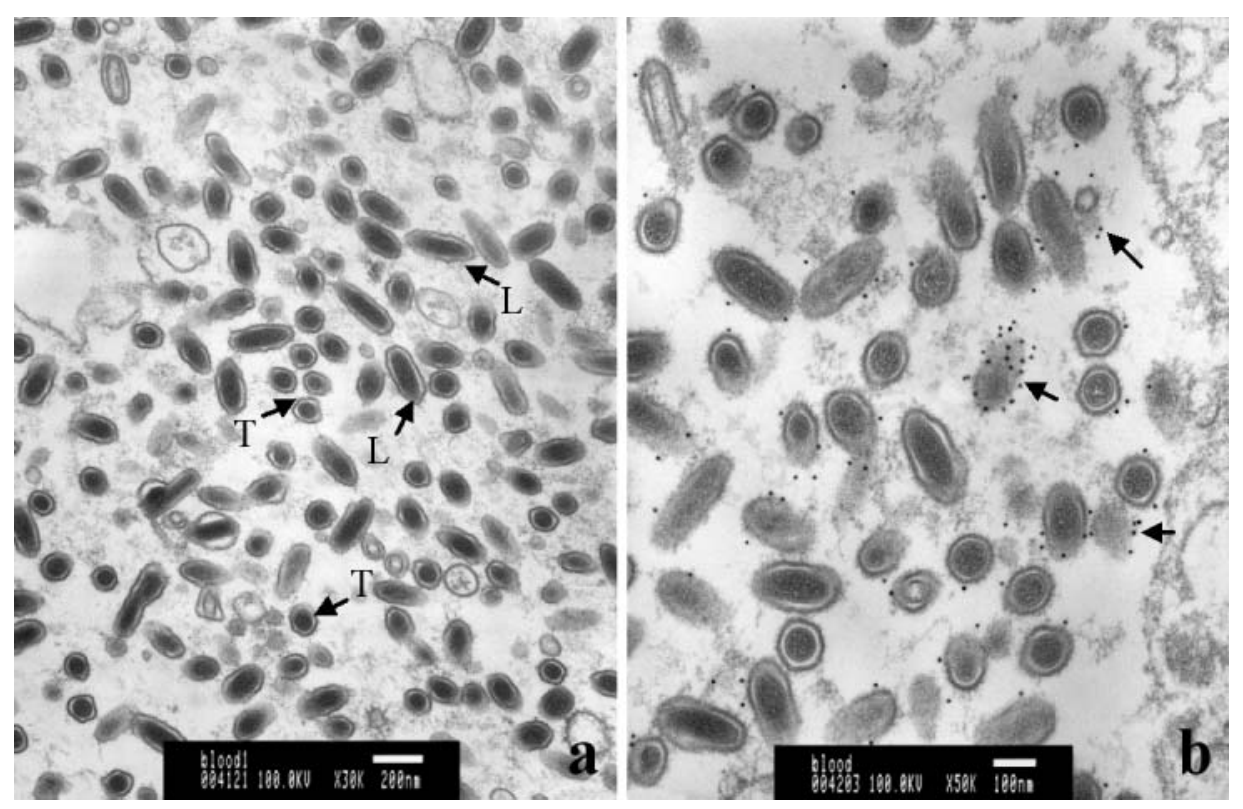

Fig. 2. Penaeus merguiensis. Transmission electron micrographs of WSSV virions collected from hemolymph, analyzed by immunogold-TEM, and negatively stained. (a) Intact virions (arrows); (b) gold particles (arrows) attached to envelopes of virions. T: crosssection, L: longitudinal section whereas the HC number was not reduced significantly. Thus WSSV infection exhibited a clear selective association with the hemocyte subpopulation of the shrimp.

\section{Characterization of hemocytes and immunofluorescence assay (IFA)}

All 3 types of hemocytes were further characterized by Wright-Giemsa staining, and examined under the phase-contrast microscope. The granular cells (GCs) were the largest among the hemocytes and featured large refractile granules in the cytoplasm and a low nucleus-to-cytoplasm ratio (Fig. 4a). The semigranular cells (SGCs), which were larger than the HCs, contained numerous small granules in the cytoplasm (Fig. $4 \mathrm{~d}-\mathrm{g}$ ). The non-granulated hyaline cells (HCs) were the smallest cells among the hemocytes and characterized by a high nucleus-to-cytoplasm ratio. They contained a large and round nucleus in the central position, occupying almost all the cell (Fig. 4j). After the double IFAGiemsa staining, fluorescent dots were found in both SGCs and GCs, suggesting the presence of WSSV in these cells. When the IFA image and Wright-Giemsa staining were merged, the sites of localization of the WSSV became obvious. In SGCs, the fluorescent dots were detected in the cytoplasm as well as in the nucleus (Fig. 4e,f,h,i). In GCs, on the other hand, only a few fluorescent dots were detected in the cytoplasm (Fig. 4b,c). No fluorescence was detected in the HCs (Fig. $4 \mathrm{k}, 1$ ). In the negative control, only a secondary antibody was added, which abolished the positive fluorescence signal. These results suggest that the GCs and SGCs are the cells affected by WSSV infection,
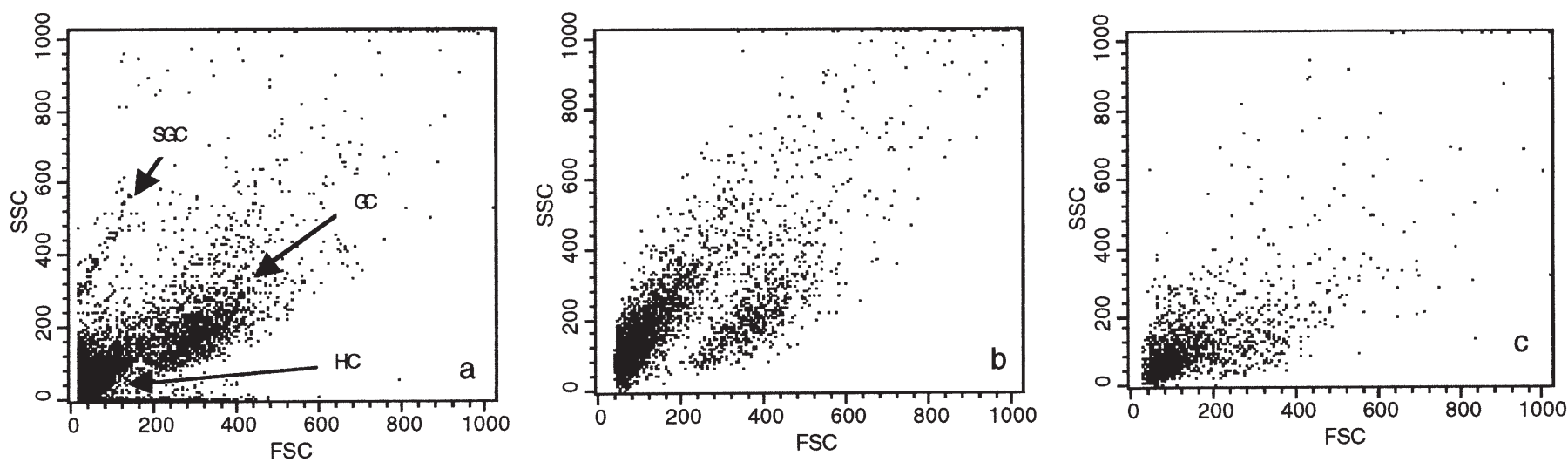

Fig. 3. Penaeus merguiensis. Analysis of hemocyte subpopulations (GC: granular cells; SGC: semigranular cells; HC: hyaline

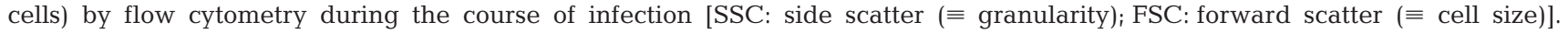

(a), (b), (c) Days 1, 3 and 5 of the experiment 
and that these hemocytes could disseminate the virus systemically through body circulation.

In addition, 10 batches of shrimp were pooled and sorted, and examined by IFA under a phase-contrast microscope for 3 consecutive days (Days 1,2 and 3 of the experiment) for changes in the percentage of hemocytes infected with WSSV. No significant difference was found among these batches. We counted the number of infected hemocytes/total hemocytes $(10 \times$ 100, 5 fields) for each type of hemocyte in 2 batches, and the statistical results of these 2 batches again were not significantly different (Table 1). The average infection rate of these 2 batches of shrimp is shown in Fig. 5. On the first day of the experiment, the average percentage of infected SGCs was $8 \%$, GCs $5 \%$, and no infection was found in HCs. Interestingly, on the second and third day of the experiment, the average percentage of infected SGCs increased rapidly to 21 and $65 \%$, respectively. The increase in percentage of the infected GCs was less dramatic, being 7 and $23 \%$,

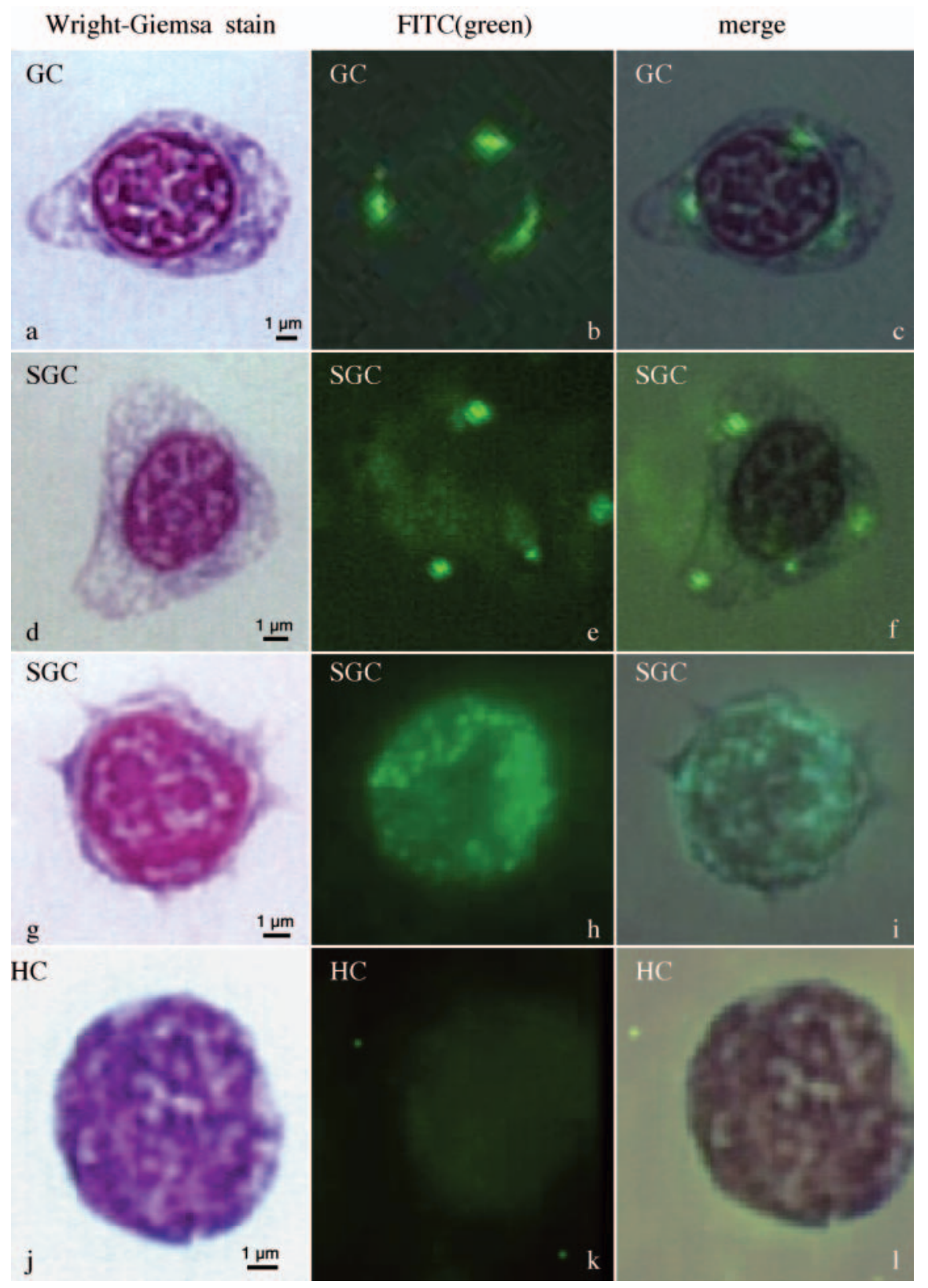

Fig. 4. Penaeus merguiensis. Detection of WSSV in infected hemocytes by double staining using WSSV-specific Mab and WrightGiemsa staining. (a), (d), (g), (j) are stained with Wright-Giemsa stain; green images in (b), (e), (h), (k) represent images obtained from FITC-derived green fluorescence; merged images in (c), (f), (i), (l) show localization of virus particles in the hemocytes.

For abbreviations, see Fig. 3 
Table 1. Penaus merguiensis. Comparison of numbers of hemocytes infected with WSSV on Days 1, 2 and 3. Inf./total: no of infected hemocytes/total hemocytes $(10 \times 100,5$ fields); \%: average ratio

\begin{tabular}{|c|c|c|c|c|c|c|}
\hline \multirow{2}{*}{$\begin{array}{l}\text { Hemocyte } \\
\text { type }\end{array}$} & \multicolumn{2}{|c|}{$\longrightarrow$ Day $1 \longrightarrow$} & \multicolumn{2}{|l|}{ - Day 2} & \multirow{2}{*}{$\begin{array}{l}\text { Day } 3 \\
\text { Inf./total }\end{array}$} & \multirow[b]{2}{*}{$\%$} \\
\hline & Inf./total & $\%$ & Inf./total & $\%$ & & \\
\hline \multicolumn{7}{|l|}{ Batch 1} \\
\hline GC & $1 / 17,1 / 23,2 / 28,1 / 31,1 / 19$ & 5.08 & $2 / 22,1 / 18,2 / 27,3 / 30,0 / 18$ & 6.95 & $6 / 26,3 / 16,5 / 20,3 / 17,7 / 25$ & 23.07 \\
\hline SGC & $2 / 18,1 / 13,2 / 21,1 / 16,1 / 20$ & 7.95 & $5 / 24,4 / 19,6 / 27,5 / 23,4 / 21$ & 21.00 & $14 / 20,12 / 17,14 / 23,13 / 22,13 / 19$ & 65.03 \\
\hline $\mathrm{HC}$ & $0 / 23,0 / 21,0 / 17,0 / 19,0 / 20$ & 0 & $0 / 30,0 / 22,0 / 27,0 / 19,0 / 21$ & 0 & $0 / 23,0 / 18,0 / 20,0 / 22,0 / 25$ & 0 \\
\hline \multicolumn{7}{|l|}{ Batch 2} \\
\hline GC & $1 / 21,2 / 27,0 / 16,1 / 17,1 / 20$ & 4.95 & $2 / 27,2 / 30,2 / 24,1 / 20,2 / 27$ & 7.03 & $5 / 22,2 / 15,5 / 20,4 / 20,6 / 23$ & 23.00 \\
\hline SGC & $2 / 23,0 / 15,2 / 21,2 / 23,2 / 18$ & 8.00 & $5 / 22,6 / 24,3 / 19,3 / 19,5 / 20$ & 21.00 & $14 / 25,13 / 18,12 / 19,13 / 20,14 / 22$ & 65.08 \\
\hline $\mathrm{HC}$ & $0 / 19,0 / 17,0 / 27,0 / 21,0 / 23$ & 0 & $0 / 24,0 / 20,0 / 23,0 / 27,0 / 29$ & 0 & $0 / 18,0 / 27,0 / 20,0 / 17,0 / 22$ & 0 \\
\hline
\end{tabular}

respectively. However, infection in HCs was undetectable throughout the study. Our data showed that among all types of hemocytes, the SGCs were most highly susceptible to WSSV infection, showing a higher virus load and infection rate compared to GCs.

\section{Analysis of infection of hemocytes by transmission electron microscopy (TEM)}

The IFA results were further comfirmed by a TEM study. As shown in Fig. 6a, the differences among the 3 hemocyte types were very clear. No virus was detected in HCs (Fig. 6a,b). The cytoplasm of GCs contains several large irregular granules and vacuoles. the electron microscopy study revealed that the virus particles were localized in the vacuoles of the cytoplasm (Fig. 6c,d). In contrast, the SGCs are irregular in shape, with many digitations and spherical cytoplasmic granules. Similar to GCs, virus particles were found in the cytoplasmic vacuoles of SGCs (Fig. 6e-h). However, at higher magnification, clusters of developing virions and mature

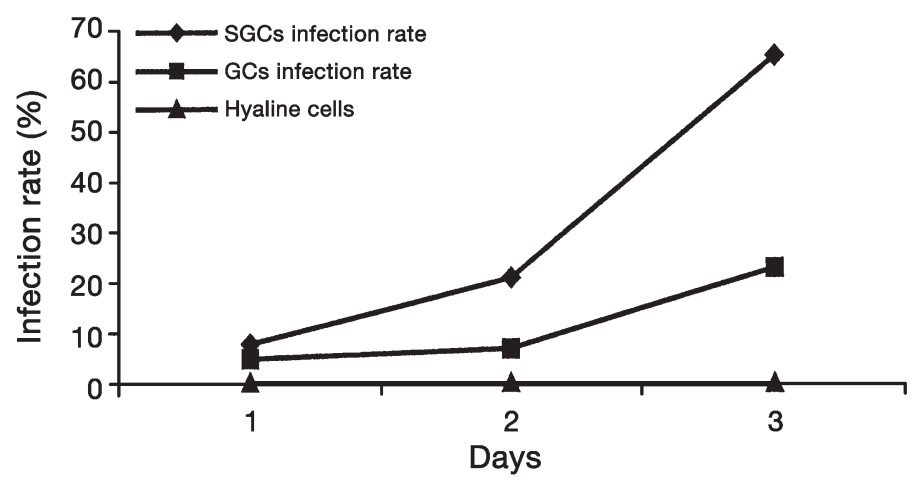

Fig. 5. Penaeus merguiensis. Number of infected GCs and SGCs continuously increased during infection. The infection rate at each time point is expressed as the average percentage of infected cells of each type, based on the immunofluorescence assay (IFA)/total no. of cells counted in 5 fields under the microscope virions were also found in the nucleus of SGCs (Fig. 6i-k). Even the morphogenesis of WSSV in the infected nucleus of heavily infected SGCs was observed. The nucleus was filled with many empty premature nucleocapsids, most of which were surrounded loosely with an envelope, with both the shell and envelope open at the same end (Fig. 6i-k).

\section{DISCUSSION}

Although the current understanding of the penaeid shrimp immune system is incomplete, it is well known that the components of hemolymph play a vital role in disease prevention through an array of mechanisms. The data reported in this study clearly established a specific association of the WSSV pathogen with hemocyte subpopulations. In the tiger shrimp Penaeus monodon, responses to the invasion of foreign materials include phagocytosis, nodule formation, activation of the prophenoloxidase system, and production of superoxide anion and hydrogen peroxide (Sung et al. 1996, 1998). In penaeid shrimp, phenoloxidase (PO) is the main chemical mediator produced by GCs, whereas acid phosphatase is mainly produced by SGCs. The HCs and the granulocytes (GC and SGC) were divided into 2 morphologically and functionally distinct cell lineages (Hose et al. 1990). The HCs were unstable hemocytes, nonphagocytic, and were primarily involved in coagulation of hemolymph; both GCs and SGCs are actively phagocytic (Omori et al. 1989, Gargioni \& Barracco 1998, Hose et al. 1990). In contrast, Lee et al. (2001) demonstrated that both HCs and SGCs are potentially phagocytic. Although the role of HCs in the shrimp's defence mechanim is not clear, GCs and SGCs inevitably played a major role.

Tsai et al. (1999) reported that the WSSV infection in shrimps can be divided into 3 states: the asymptomatic carrier state, the transition state and the patent state. Under certain stress conditions, such as collection, 


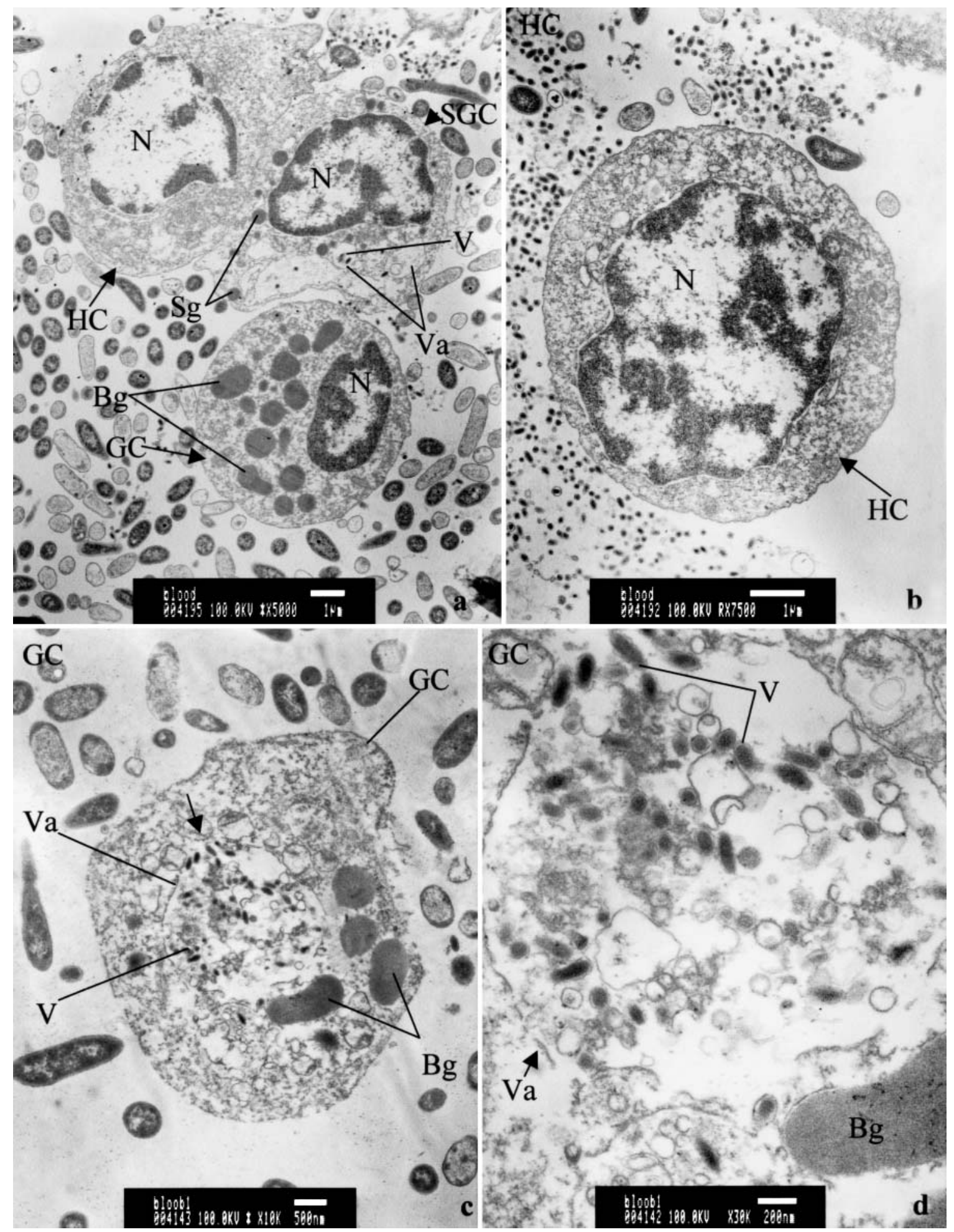

Fig. 6. (Above and following 2 pages) Penaeus merguiensis. Electron micrographs of uninfected and WSSV-infected hemocytes. (a) GC, SGC and HC hemocytes; (b) non-infected HC; (c) virions found in vacuole of infected GC; (d) enlarged view of vacuole arrowed in (c) showing the WSSV virions; (e), (g) WSSV virions in the vacuoles of infected SGC; (f), (h) enlarged view of vacuoles arrowed in (e) and (g), respectively, showing the WSSV virions; (i) many WSSV virions in the nucleus of heavily infected SGC; (j) enlarged view of the nucleus arrowed in (i) showing premature WSSV virions in the nucleus of SGC; $(\mathrm{k})$ mature WSSV virions in the nucleus of heavily infected SGC. N: nucleus; Bg: large granule; Sg: small granule; Va: vacuole; V: WSSV virion 


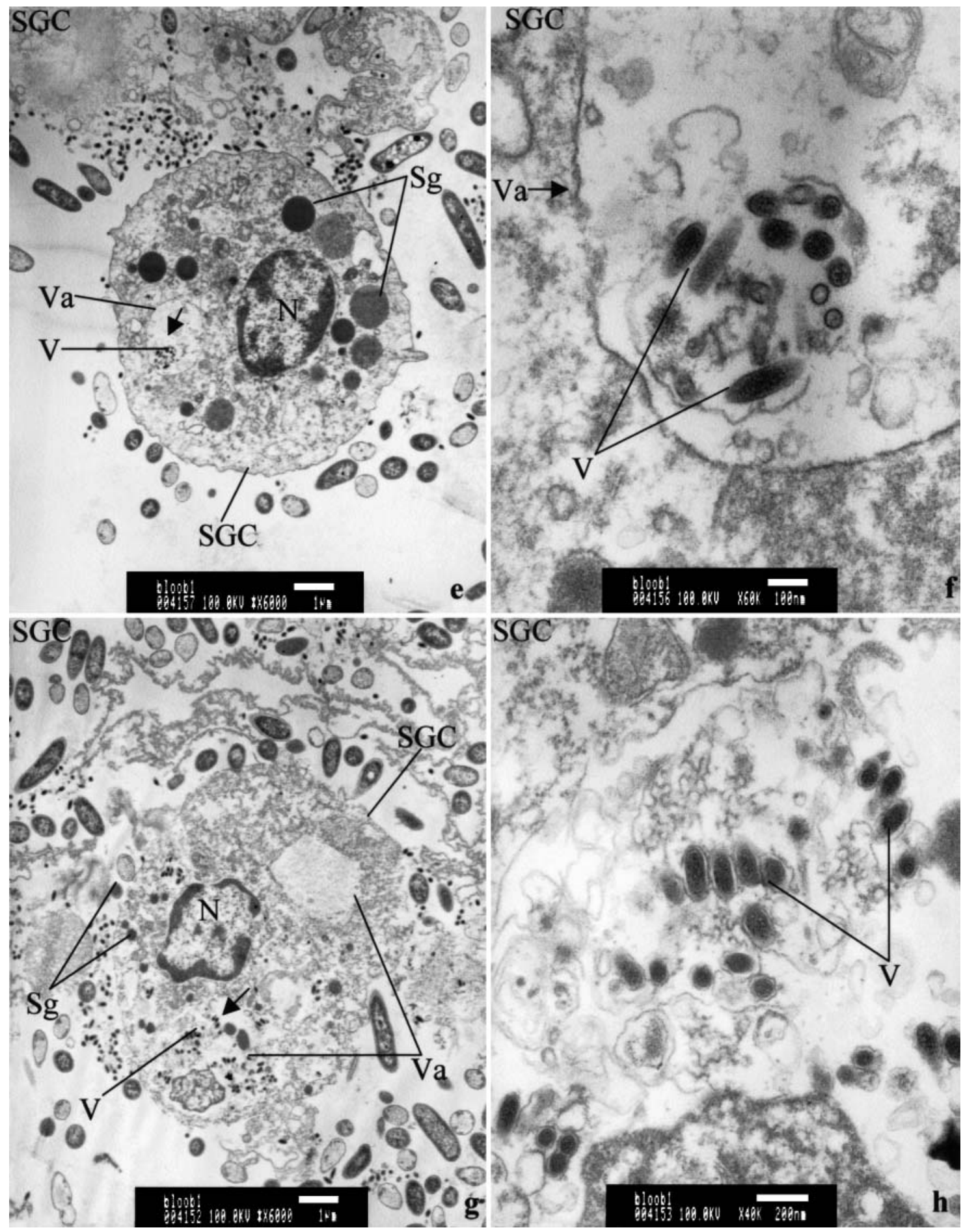

Fig. 6 (continued)

transportation and poor-water quality, the carrier state may be triggered rapidly towards the transition state and eventually the patent state (Song et al. 1997, Tsai et al. 1999). In our pilot study, attempts to use healthy shrimp (no visible clinical symptoms) as WSSV-free shrimp were unsuccessful. In such individuals, WSSV was detected by PCR using primers specific to ORF 144, but was not detected either by electron microscopy or by direct virus isolation from their hemolymph. Therefore, asymptomatic carriers were used as samples in our experiment. The progression of the disease found in this study fits that of the proposed 3-state 

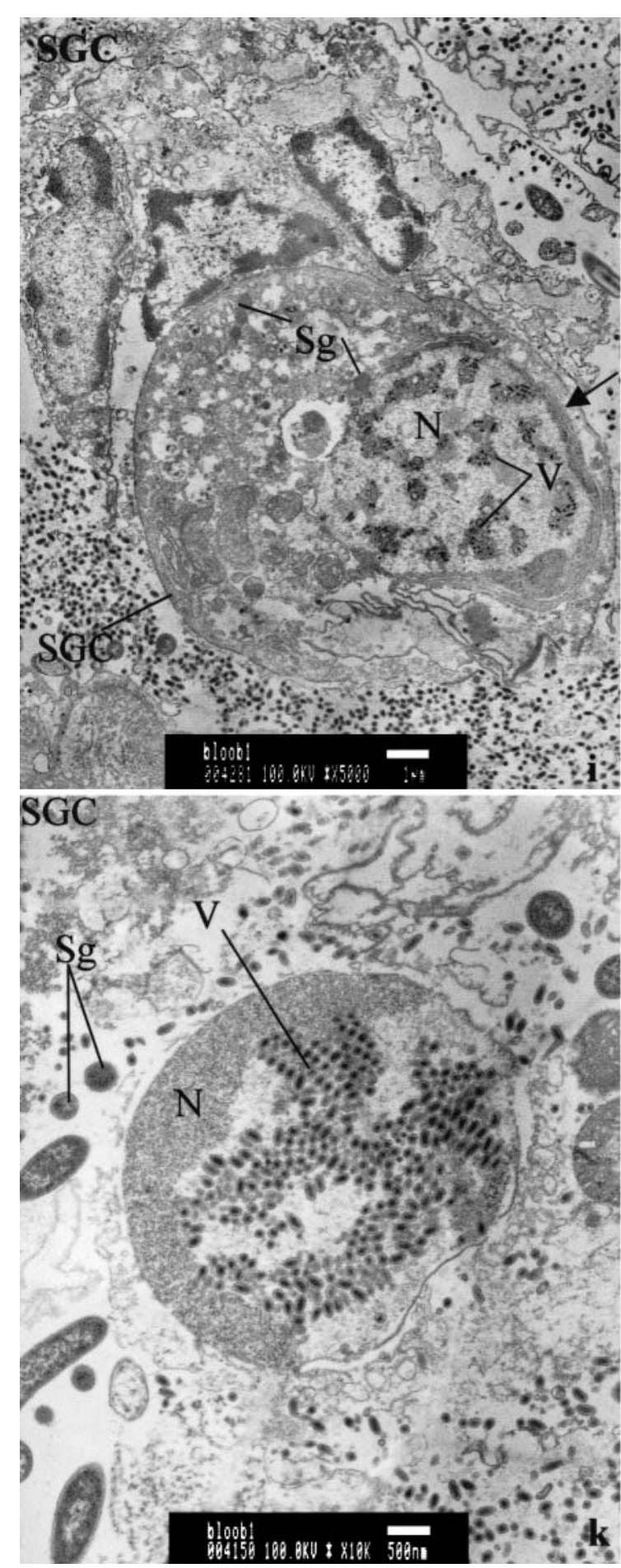

WSSV infection, and the mortality rate of shrimp reached $100 \%$ by Day 5 . We therefore defined the day of arrival (Day 1) as the onset of the transition state. In the asymptomatic carrier state, the amount of WSSV is so low that even some PCR detection systems failed to diagnose the virus due to their poor sensitivity (Lo et al.

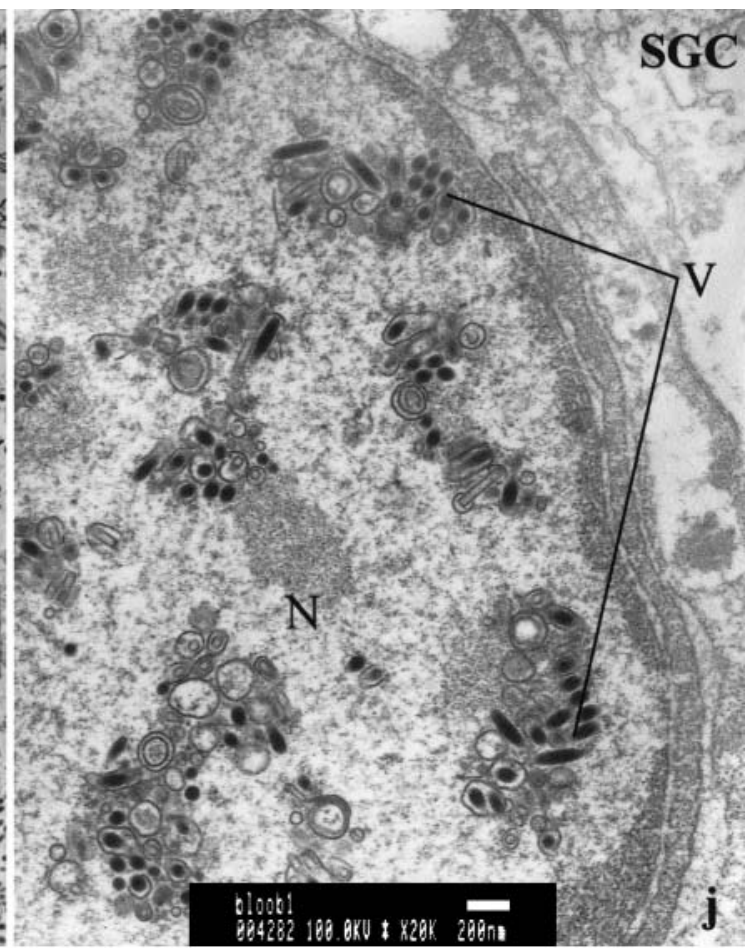

Fig. 6 (continued)

1996a,b). We tried several different primer pairs targeted on various WSSV ORFs, but only the PCR primers specific to ORF 144 gave a satisfactory detection. Our previous studies (data not shown) showed that the primers (144F/144R) corresponding to ORF 144 of WSSV exhibited a comparable sensitivity to that of Primers 146F1/146R1 and 146F2/146R2 described in a 2-step PCR (Lo et al. 1996b, Peng et al. 1998). It is easier to perform a 1-step PCR than a 2-step PCR. Therefore, we selected a pair of primers corresponding to the 144 ORF of the WSSV, which could sensitively and specifically amplify a $282 \mathrm{bp}$ product from shrimps at different states of infection and under various conditions.

Previously, Dall (1964) classified hemocytes into 3 broad categories according to morphological criteria. These criteria were mainly based on observations under both light and electron microscopy. However, the identification by morphology alone might be problematic because the granulated cells are highly polymorphic. Identification of hemocytes in crustaceans using Mabs has been reported (Rodriguez et al. 1995, Sung et al. 1999, van de Braak et al. 2000). Another approach to separating the 3 types of hemocytes, such as isopycnic centrifugation in a discontinuous Percoll gradient, has been reported (Rodriguez et al. 1995). The flow cytometry approach employed in this study offers several advantages compared to microscopy, as it is possible to analyze individual cell types, and to sort and harvest 
a particular kind of cell within a short period of time. Recently, this approach has been used in several studies of shrimp hemocytes (Sequeira et al. 1996, Lee et al. 2001). Using a cell sorter, we have sorted and harvested each type of the 3 hemocytes for further study.

Microscopic examination of hemolymph of penaeid shrimps has shown that the GCs and HCs are represented equally, whereas SGCs make up about $10 \%$ of the total hemocyte population (Lee et al. 2001). In the present study, flow cytometry analysis showed a ratio of hemocytes similar to that reported by Lee et al. on Day 1 of the experiment. However, the SGCs subpopulation was estimated to occupy $5 \%$ of the total hemocytes instead of $10 \%$ (Fig. 3a). The later stages of WSSV infection led to a significant alteration in the ratio of the hemocyte populations, followed by cellular disintegration. The altered ratio of hemocyte populations was not due to other physiological factors such as molting. It has been reported that certain crustacean hemocytes may change their shape and degranulate rapidly in vitro (Soderhall \& Smith 1983, Martin \& Graves 1985, Soderhall \& Cerenius 1992, Rodriguez et al. 1995), but we solved this problem by the use of fixed hemolymph which minimized disruption of cellular integrity. Also, it has been reported that the relative percentage of the 3 types of hemocytes do not show any appreciable changes during the entire molt cycle (Tsing et al. 1989, Le Moullac et al. 1997). Therefore the above considerations do not affect our interpretation of the changes in hemocyte ratio.

It has been reported that WSSV mainly occurs in the nuclei of infected lymphoid cells (Wang et al. 2000a). Itami et al. (1999) reported that the large GCs were insensitive to WSSV under culture conditions. However, our study based on IFA and TEM showed that the GCs and SGCs, 2 of 3 types of hemocytes found in hemolymph, were the targets for WSSV infection (Table 1, Figs. 4 \& 6). Hemolymph collected from live shrimp harbored numerous mature virions and incompletly assembled viral particles in the nucleus of SGCs, as shown in Fig. 6e-j, indicating that virus replication took place in the SGCs. On the other hand, intact virus particles found in the cytoplasmic vacuoles, but not in the nuclei of GCs, were possibly due to virus infection/replication, phagocytosis or endocytosis. Flow cytometric data further support the conclusion that the 2 hemocyte populations are the targets for the WSSV infection (Fig. 3a-c).

Shrimp hemolymph was directly placed in formalin solution for fixation and then sorted and harvested by flowcytometry prior to light microscopy examination, thus minimising the risk of $\mathrm{HCs}$ being lyzed rapidly in vitro. Nevertheless, we can not rule out the possibility of a mechanism of rapid replacement of infected HCs by newly formed HCs in vivo. The destruction of the im- mune mediators, GCs and SGCs, in their hemolymph could seriously damage the immune system of shrimp. Such compromised immunity could render the shrimp sensitive to any extrinsic factors. This may explain why, upon WSSV infection, the cumulative mortality of the cultured shrimp can reach $100 \%$, resulting in enormous economic losses to the shrimp-culture industries worldwide. In conclusion, our studies suggested that the hemocytes, particularly the GCs and SGCs, are the targets of WSSV infection. The SGCs are more susceptible to WSSV infection, contain more virus particles, and exhibit a much faster infection rate than GCs.

Acknowledgements. This work was funded by the National Sciences and Technology Board (NSTB), Singapore. We thank Mr. Qinwen Lin and Ms. Yangsun Chan for their great help with the electron microscopy.

\section{LITERATURE CITED}

Chang PS, Lo CF, Wang YC, Kou GH (1996) Identification of white spot syndrome associated baculovirus (WSSV) target organs in shrimp, Penaeus monodon, by in situ hybridization. Dis Aquat Org 27:131-139

Dall W (1964) Studies on the physiology of a shrimp, Metapenaeus mastersii (Haswell) (Crustacea: Decapoda: Penaeidae). I. Blood constituents. Aust J Mar Freshw Res 15: 145-161

Flegel TW (1997) Major viral diseases of the black tiger prawn (Penaeus monodon) in Thailand. World J Microbiol Biotechnol 13:433-442

Flegel TW, Fegan DF, Sriurairatana S (1995) Environmental control of infectious disease in Thailand. In: Browdy CL, Hopkins JS (eds) Swimming through troubled water. Proc Special Session on Shrimp Farming, Aquaculture '95. World Aquaculture Society, Baton Rouge, LA, p 65-79

Gargioni R, Barracco MA (1998) Hemocytes of the palaemonids Macrobrachium rosenbergii and M. acanthurus, and of the penaeid Penaeus paulensis. J Morphol 236: 209-221

Hose J, Martin GG (1989) Defense functions of granulocytes in the ridgeback prawn Sicyonia ingentis. J Invertebr Pathol 53:335-346

Hose JE, Martin GG, Gerard AS (1990) A decapod classification scheme integrating morphology, cytochemistry, and function. Biol Bull 178:33-45

Huang J, Song XL, Yu J, Yang CH (1995) Baculoviral hypodermal and hematopoietic necrosis-study on the pathogen and pathology of the explosive epidemic disease of shrimp. Mar Fish Res (Shandong) 16:1-10

Inouye $\mathrm{K}$, Miwa $\mathrm{S}$, Oseko $\mathrm{N}$, Nakano $\mathrm{H}$, Kimura T, Momoyama K, Hiraoka M (1994) Mass mortalities of cultured kuruma shrimp Penaeus japonicus in Japan in 1993: electron microscopic evidence of the causative virus. Fish Pathol 29:149-158

Itami T, Maeda M, Kondo M, Takahashi Y (1999) Primary culture of lymphoid organ cell and haemocytes of kuruma shrimp, Penaeus japonicus. Methods Cell Sci 21:237-244

Le Moullac GL, Le Groumellec ML, Ansquer D, Froissard S, Levy P, Aquacop (1997) Haematological and phenoloxidase activity changes in the shrimp Penaeus stylirostris in relation with the molt cycle: protection against vibriosis. Fish Shellfish Immunol 7:227-234 
Lee YK, Soh BS, Wu JH (2001) Quantitative assessment of phagocytic activity of hemocytes in the prawn, Penaeus merguiensis, by flow cytometric analysis. Cytometry 43:82-85

Lightner DV (1996) A handbook of shrimp pathology and diagnostic procedures for diseases of cultured penaeid shrimp. World Aquatic Society, Baton Rouge, LA

Liu W, Wang YT, Tian DS, Yin ZC, Kwang J (2002) Detection of white spot syndrome virus (WSSV) of shrimp by means of monoclonal antibodies (Mabs) specific to an envelope protein (28 kDa). Dis Aquat Org 49:11-18

Lo CF, Ho CH, Peng SE, Chen CH and 7 others (1996a) White spot syndrome baculovirus (WSBV) detected in cultured and captured shrimp, crabs and other arthropods. Dis Aquat Org 27:212-215

Lo CF, Leu JH, Ho CH, Chen CH and 8 others (1996b) Detection of baculovirus associated with white spot syndrome baculovirus (WSBV) in penaeid shrimps using polymerase chain reaction. Dis Aquat Org 25:133-141

Lo CF, Hsu HC, Tsai MF, Ho CH, Peng SE, Kou GH, Lightner DV (1999) Specific genomic fragment analysis of different geographical clinical samples of white spot syndrome virus. Dis Aquat Org 35:175-185

Lockwood APM (1968) Aspects of the physiology of Crustacea. Oliver \& Boyd, Edinburgh

Martin GG, Graves BL (1985) Fine structure and classification of shrimp hemocytes. J Morphol 185:339-348

Omori SA, Martin GG, Hose JE (1989) Morphology of hemocyte lysis and clotting in the ridgeback prawn Sicyonia ingentis. Cell Tissue Res 255:17-23

Peng SE, Lo CF, Ho CH, Chang CF, Kou GH (1998) Detection of white spot baculovirus (WSBV) in giant freshwater prawn, Macrobrachium rosenbergii, using polymerase chain reaction. Aquaculture 164:253-262

Rodriguez J, Boulo V, Mialhe E, Bachere E (1995) Characterization of shrimp hemocytes and plasma components by monoclonal antibodies. J Cell Sci 108:1043-1050

Sequeira T, Tavares D, Arala-Chaves M (1996) Evidence for circulating hemocyte proliferation in the shrimp Penaeus japonicus. Dev Comp Immunol 20:97-104

Soderhall K, Cerenius L (1992) Crustacean immunity. Annu Rev Fish Dis 2:3-23

Soderhall K, Smith VJ (1983) Separation of hemocyte populations of Carcinus maenas and other marine decapods, and prophenoloxidase distribution. Dev Comp Immun 7: $229-239$

Editorial responsibility: Hans von Storch, Geesthacht, Germany
Song YL, Liu JJ, Chan LC, Sung HH (1997) Glucan-induced disease resistance in tiger shrimp (Penaeus monodon). Dev Biol Stand 90:413-421

Sung HH, Yang YL, Song YL (1996) Enhancement of microbicidal activity in the tiger shrimp Penaeus monodon via immunostimulation. J Crustac Biol 16:278-284

Sung HH, Chang HJ, Her CH, Chang JC, Song YL (1998) Phenoloxidase activity of hemocytes derived from Penaeus monodon and Macrobrachium rosenbergii. J Invertebr Pathol 71:26-33

Sung HH, Wu PY, Song YL (1999) Characterization of monoclonal antibodies to hemocyte subpopulations of tiger shrimp (Penaeus monodon): immunochemical differentiation of three major hemocyte types. Fish Shellfish Immunol 9:167-179

Tsai MF, Kou GH, Liu HC, Liu KF and 5 others (1999) Longterm presence of white spot syndrome virus (WSSV) in a cultivated shrimp population without disease outbreaks. Dis Aquat Org 38: 107-144

Tsing A, Arcier JM, Brehelin M (1989) Hemocytes of penaeid and palaemonid shrimps: morphology, cytochemistry, and hemograms. J Invertebr Pathol 53:64-77

van de Braak CBT, Taverne N, Botterblom MHA, van de Knaap WPW, Rombout JHWM (2000) Characterisation of different morphological features of black tiger shrimp (Penaeus monodon) haemocytes using monoclonal antibodies. Fish Shellfish Immunol 10:515-530

van Hulten MCW, Witteveldt J, Peters S, Kloosterboer N and 5 others (2001) The white spot syndrome virus DNA genome sequence. Virology 286:7-22

Wang CH, Lo CF, Leu JH, Chou CM and 6 others (1995) Purification and genomic analysis of baculovirus associated with white spot syndrome (WSBV) of Penaeus monodon. Dis Aquat Org 23:239-242

Wang $\mathrm{CH}$, Yang $\mathrm{HN}$, Tang $\mathrm{CY}$, Lu CH, Kou GH, Lo CF (2000a) Ultrastructure of white spot syndrome virus development in primary lymphoid organ cell cultures. Dis Aquat Org 41:91-104

Wang Q, Nunan LM, Lightner DV (2000b) Identification of genomic variations among geographic isolates of white spot syndrome virus using restriction analysis and southern blot hybridization. Dis Aquat Org 43:175-181

Yang F, He J, Lin XH, Li Q, Pan D, Zhang XB, Xu X (2001) Complete genome sequence of the shrimp white spot bacilliform virus. J Virol 75:11811-11820

Submitted: December 26, 2001; Accepted: July 17, 2002 Proofs received from author(s): December 2, 2002 